\title{
PELATIHAN PEMBUATAN SABUN MANDI PADAT DENGAN \\ PENAMBAHAN MINYAK ATSIRI JERUK KALAMANSI SEBAGAI AROMATERAPI DI SMPIT KHAIRUNNAS BENGKULU
}

\author{
Dyah Fitriani, Eni Widiyati, dan Bambang Trihadi \\ MIPA, Kimia, Universitas Bengkulu \\ E-mail : dyah.fitriani@unib.ac.id
}

\begin{abstract}
ABSTRAK
Sabun mandi adalah senyawa natrium atau kalium dengan asam lemak dari minyak nabati dan atau lemak hewani berbentuk padat, lunak atau cair, digunakan sebagai pembersih dengan menambahkan zat pewangi dan bahan lainnya yang tidak membahayakan kesehatan. Bahan baku utama sabun adalah minyak dan lemak yang direaksikan dengan senyawa alkali sehingga terjadi reaksi saponifikasi atau penyabunan. Agar sabun yang dihasilkan memiliki aroma yang wangi, dapat ditambahkan zat aditif yang berupa minyak atsiri. Minyak atsiri banyak ditemukan pada tanaman, salah satunya adalah jeruk kalamansi. Atsiri yang berasal dari tanaman ini mempunyai sifat sebagai aromaterapi, yang mempunyai efek menenangkan dan berguna bagi kesehatan. Tanaman jeruk kalamansi merupakan tanaman khas provinsi Bengkulu. Oleh karenanya, minyak atsiri yang berasal dari jeruk kalamansi ini akan digunakan sebagai bahan aditif pada pembuatan sabun mandi padat sebagai aromaterapi. Pelatihan pembuatan sabun mandi padat dengan minyak atsiri sebagai aromaterapi telah dilakukan di SMPIT KHAIRUNNAS Bengkulu. Pada pelatihan ini, siswa diberikan teori tentang sabun dan bagaimana proses pembuatannya disertai dengan siswa ikut mempraktekkan pembuatan sabun. Dari kegiatan ini, diharapkan siswa mengetahui dan memahami cara pembuatan sabun mandi padat aromaterapi.
\end{abstract}

Kata Kunci: sabun mandi, minyak atsiri jeruk kalamansi

\section{PENDAHULUAN}

Sabun mandi adalah senyawa natrium atau kalium dengan asam lemak dari minyak nabati dan atau lemak hewani berbentuk padat, lunak atau cair, digunakan sebagai pembersih, dengan menambahkan zat pewangi, dan bahan lainnya yang tidak membahayakan kesehatan. Di pasaran, sabun memiliki berbagai aroma yang menjadikan produk sabun tersebut menarik dan digunakan masyarakat untuk kebutuhan kulit tubuh. Kulit merupakan bagian terpenting dari tubuh yang melindungi bagian dalam tubuh dari gangguan panas atau dingin dan gangguan kuman (Sukawaty et al., 2016).

Bahan baku utama sabun adalah minyak dan lemak yang direaksikan dengan senyawa alkali sehingga terjadi reaksi saponifikasi atau penyabunan. Salah satu minyak yang dapat digunakan untuk membuat sabun adalah Virgin Coconut Oil (VCO) atau yang 
dikenal dengan minyak kelapa virgin. VCO adalah salah satu produk olahan buah kelapa yang memiliki banyak manfaat, karena komposisi penyusun terdiri dari asam lemak dengan rantai sedang yang dapat menjaga kesehatan tubuh dan mencegah berbagai penyakit (Sinaga et al., 2017).VCO mengandung asam laurat yang tinggi sekitar 46,3648,42\% (Mansor et al., 2012). Asam laurat merupakan medium chain fatty acid (MCFA) yang memiliki nilai nutrisi dan fungsional sangat baik (Diyah et al., 2010). Minyak VCO tidak berwarna (jernih), tidak mudah tengik dan tahan bertahun tahun jika disimpan.

Struktur kimia $V C O$ berupa trigliserida, merupakan triester dari gliserol dengan asam lemak suku tinggi. Apabila VCO direaksikan dengan $\mathrm{NaOH}$ maka akan dihasilkan sabun seperti sabun mandi yang banyak digunakan dalam kehidupan sehari-hari. Asam lemak jenuh yang terdapat pada minyak kelapa lebih tinggi dari pada minyak sawit, minyak kacang tanah, minyak kedelai, minyak jagung dan minyak bunga matahari (Tuminah, 2009).

Sabun mandi padat yang telah banyak dikenal oleh masyarakat pada umumnya mempunyai aroma yang wangi.. Tentu saja, selain sabun berfungsi untuk membersihkan kotoran yang menempel di badan, konsumen juga ingin tubuhnya menjadi wangi setelah memakai sabun. Pewangi yang biasanya ditambahkan pada sabun dapat berasal dari parfum sintetis maupun dari minyak atsiri yang diperoleh dari tanaman. Salah satu tanaman ini yang dapat menghasilkan minyak atsiri yaitu jeruk kalamansi. Jeruk ini merupakan tanaman khas provinsi Bengkulu yang kemudian dapat diolah menjadi sirup. Minyak atsiri yang diperoleh dari tanaman ini dapat diambil dari residu pengolahan sirup yang telah di destilasi uap (Maryanti et al., 2017). Pewangi yang berasal dari tanaman mempunyai sifat sebagai aromaterapi, yang mempunyai efek dapat meningkatkan kondisi kesehatan dan psikologis.

Oleh karena latar belakang diatas, maka tim pengabdian pada masyarakat dari program studi kimia FMIPA UNIB ingin memberikan pengetahuan kepada masyarakat khususnya pada siswa di SMPIT KHAIRUNNAS Bengkulu mengenai pembuatan sabun. Pengetahuan yang akan diberikan kepada siswa antara lain mengenai mekanisme kerja sabun, bahan-bahan pembuatan sabun, dan memberikan 
pelatihan dalam bentuk praktek pembuatan sabun mandi padat yang ditambahkan minyak atsiri jeruk kalamansi sebagai aromaterapi. Dengan demikian, diharapkan dapat menambah wawasan dan pengetahuan para siswa mengenai pembuatan sabun dan pemanfaatan bahan alam yang dapat ditemui di lingkungan sekitar mereka.

\section{METODE PELAKSANAAN}

Kegiatan Pengabdian kepada masyarakat ini dilaksanakan pada tanggal 14 Oktober 2019. Lokasi pengabdian yaitu di SMPIT KHAIRUNNAS Bengkulu yang beralamatkan di jalan Hibrida 15, kelurahan Sidomulyo, kecamatan Gading Cempaka, Kota Bengkulu. Khalayak sasaran pada kegiatan ini adalah siswa-siswi kelas IX.
Pelaksanaan kegiatan pengabdian masyarakat ini terdiri dari :

1. Memberi penjelasan kepada siswa tentang pengertian minyak atsiri dan bagaimana cara mengekstraknya dari tanaman. Pengertian sabun dan cara pembuatan sabun

2. Mempraktekkan cara pembuatan sabun dengan penambahan minyak atsiri jeruk kalamansi

3. Diskusi/Tanya Jawab, dipergunakan untuk memberi kesempatan kepada siswa SMPIT Khairunas untuk bertanya tentang hal-hal yang berhubungan dengan minyak atsiri dan pembuatan sabun dengan penambahan minyak atsiri sebagai aromaterapi.

Formulasi pembuatan sabun dapat dilihat pada tabel 1 berikut :

Tabel 1. Formulasi Pembuatan Sabun

\begin{tabular}{ccc}
\hline Bahan & Jumlah (gr) & Fungsi \\
\hline VCO & 60 & Penghasil busa \\
NaOH $30 \%$ & 20 & Pembentuk sabun \\
Asam stearat & 5 & Mengeraskan sabun \\
$\begin{array}{c}\text { Minyak atsiri jeruk } \\
\text { kalamansi } \\
\text { Akuades }\end{array}$ & 3,6 & Pewangi \\
& 11,4 & Pelarut
\end{tabular}


Diagram alur proses pembuatan sabun yaitu :
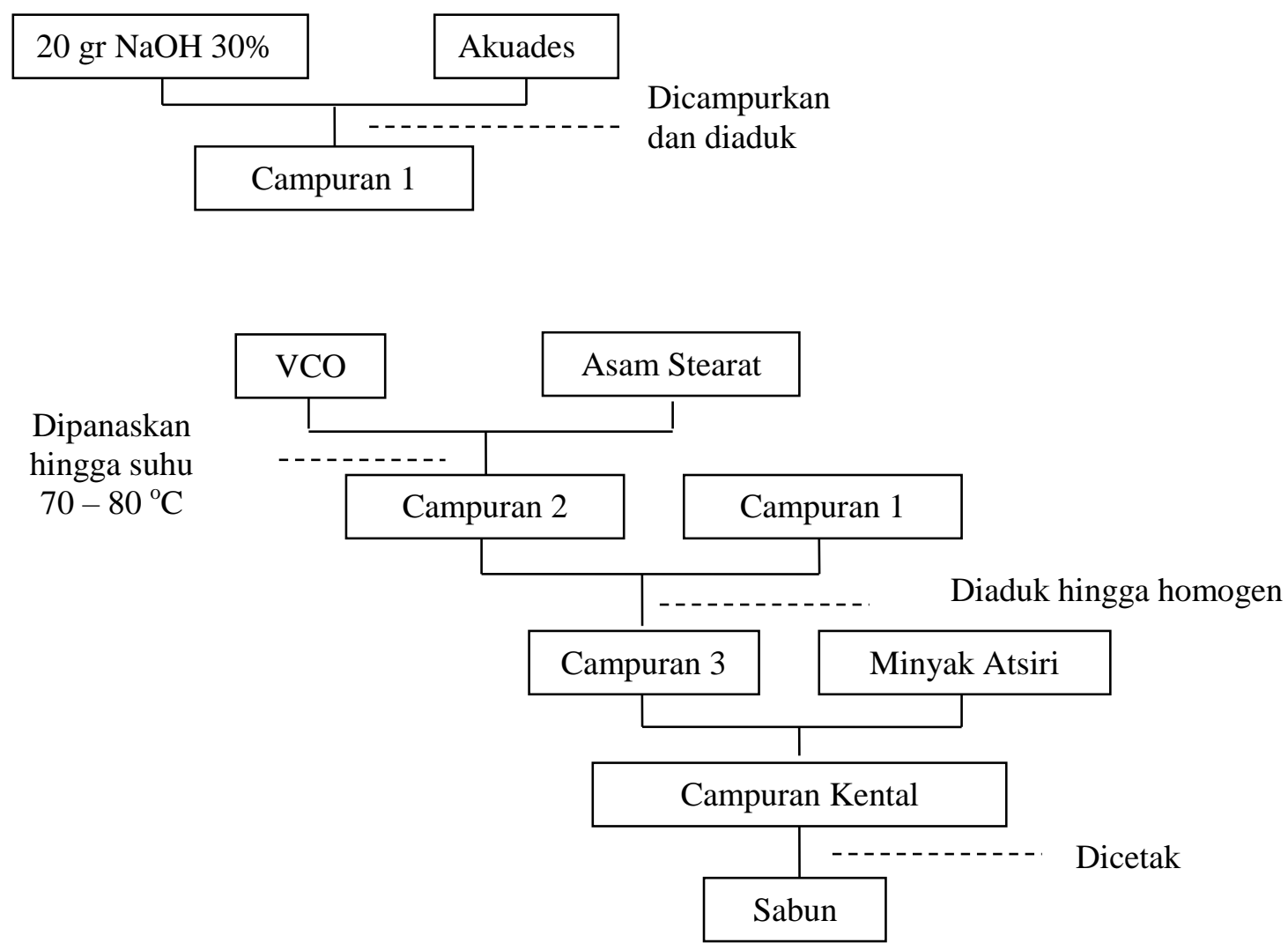

Gambar 1. Diagram Alur Proses Pembuatan Sabun

\section{HASIL DAN PEMBAHASAN}

Pada kegiatan pengabdian masyarakat ini, dihadiri oleh siswa kelas IX sebanyak 33 siswa. Kegiatan ini didahului dengan memberikan penjelasan mengenai sabun melalui media powerpoint. Pengertian sabun secara ilmu kimia, bagaimana proses sabun dapat bekerja untuk membersihkan. Setelah itu, siswa juga dikenalkan dengan pengertian apa itu minyak atsiri, darimana saja minyak atsiri dapat diperoleh dan bagaimana cara memperoleh minyak atsiri. Pada kegiatan ini digunakan minyak atsiri yang berasal dari jeruk kalamansi karena memang jeruk ini merupakan tanaman khas daerah Bengkulu. Minyak atsiri yang diperoleh berasal dari residu pembuatan sirup kalamansi dan cara perolehannya merujuk pada pengabdian yang pernah dilakukan oleh (Maryanti 
et al., 2017) yaitu dengan menggunakan alat destilasi (ekstraksi fasa cair-gas). Dari $10 \mathrm{~L}$ residu sirup kalamansi hanya dapat menghasilkan $400 \mathrm{~mL}$ minyak atsiri, berwarna bening kekuningan dan berbau khas jeruk kalamansi. Beberapa peserta kemudian diminta untuk ikut mencium bau minyak atsiri jeruk kalamansi yang sudah disediakan oleh pengabdi, agar mereka benar-benar mengenal minyak atsiri dari jeruk kalamansi. Berikut adalah gambar minyak atsiri kalamansi

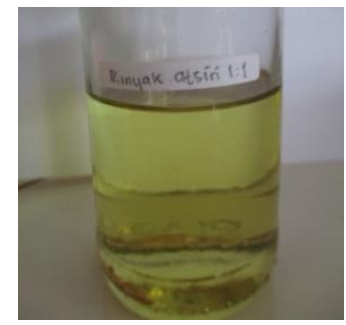

Gambar 2. Minyak Atsiri Jeruk Kalamansi

Selain minyak atsiri, dalam materi powerpoint juga dijelaskan bahan-bahan pembuatan sabun, antara lain minyak kelapa (VCO), asam stearat, $\mathrm{NaOH}$ dan akuades serta proses/alur pembuatan sabun. Agar lebih mudah dalam memahami proses pembuatan sabun, maka dilakukan pelatihan atau praktek secara langsung pembuatan sabun bersama para siswa. Adonan sabun yang baru dimasukkan ke dalam cetakan, harus didiamkan selama kurang lebih 12 jam agar adonan ini benar-benar keras, sehingga sabun yang diperoleh tidak pecah ataupun retak. Warna sabun yang dihasilkan putih kekuningan dengan aroma jeruk kalamansi. Dokumentasi praktek pembuatan sabun dapat dilihat pada Gambar 3 berikut


Gambar 3. Para Siswa Sedang Mempraktekkan Cara Pembuatan Sabun

Pada saat kegiatan berlangsung, terlihat para siswa sangat antusias dalam mengikuti kegiatan ini, apalagi di saat mereka dapat mempraktekkan 
secara langsung pembuatan sabun. Mereka jadi paham dan mengenal bahan-bahan kimia yang digunakan dalam pembuatan sabun. Pengabdi juga memberikan rambu-rambu agar siswa berhati-hati dalam berinteraksi dengan bahan kimia yang dapat membuat iritasi di kulit. Oleh karenanya, para siswa disarankan agar menggunakan alat pelindung berupa sarung tangan karet dan masker saat proses pembuatan sabun. Berikut adalah gambar sabun yang telah terbentuk dengan penambahan minyak atsiri jeruk kalamansi

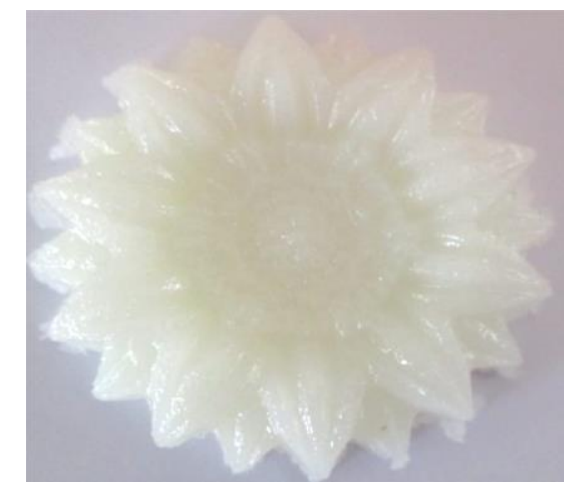

Gambar 4. Sabun Mandi Padat Aromaterapi

Penambahan minyak atsiri jeruk kalamansi berfungsi sebagai pengharum atau aromaterapi. Biasanya, konsumen tidak menyukai sabun yang tidak wangi, Oleh karenanya pemberian minyak atsiri jeruk kalamnsi bisa menjadi salah satu alternatif pewangi pada sabun. Gambar 5 merupakan dokumentasi hasil kegiatan pelatihan pembuatan sabun bersama siswa SMPIT Khairunnas

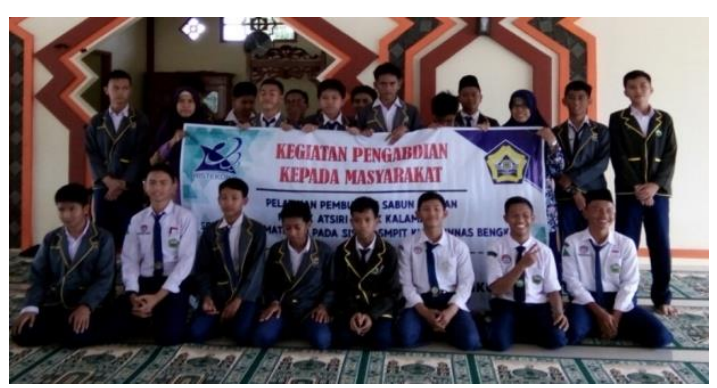

Gambar 5. Foto Bersama Peserta

Kegiatan Pengabdian Masyarakat

Dari kegiatan pengabdian masyarakat ini, diharapkan para siswa dapat memahami bagaimana proses pembuatan sabun dan pemanfaatan minyak atsiri jeruk kalamansi sebagai pewangi dan aromaterapi.

\section{KESIMPULAN}

Berdasarkan hasil dari kegiatan pengabdian masyarakat ini dapat diambil kesimpulan sebagai berikut :

\section{Siswa SMPIT KHAIRUNNAS}

Bengkulu sangat antusias dalam mengikuti pelatihan pembuatan sabun ini

\section{Siswa SMPIT KHAIRUNNAS} mengetahui cara pembuatan sabun dengan memanfaatkan minyak atsiri jeruk kalamansi sebagai aromaterapi 


\section{DAFTAR PUSTAKA}

Diyah, N.W., Purwanto, Susanti, Y. \& Dewi, Y.K., 2010. Pembuatan Minyak Kelapa Secara Enzimatis Dengan Memanfaatkan Kulit Buah dan Biji Pepaya Serta Analisis Sifat Fisikokimianya. Berk. Penel. Hayati, 15, pp.18185.

Mansor, T.S.T. et al., 2012. Physicochemical properties of virgin coconut oil extracted from different processing methods. International Food Research Journal, 3(19), pp.837-45.

Maryanti, E., Fitriani, D. \& Sani, F., 2017. Diversifikasi Produk Olahan Home Industry Sirup Jeruk Kalamansi di Kabupaten Bengkulu Tengah. Dharma Raflesia, 15(1), pp.47-54.
Sinaga, E.H., Simbolon, A.F. \& Setyaningrum, B., 2017. Pembuatan VIRGIN COCONUT OIL (VCO) Dari Kelapa Hibrida Dengan Metode Enzimatis Dan Aplikasinya Sabun Padat Transparan. Jurnal Chemurgy, 01(01), pp.16-21.

Sukawaty, Y., Warnida, H. \& Artha, A.V., 2016. Formulasi Sediaan Sabun Mandi Padat Dari Ekstrak Etanol Umbi Bawang Tiwai (Eleutherine Bulbosa (Mill.) Urb.). Jurnal Media Farmasi, 13(1), pp.14-22.

Tuminah, S., 2009. Efek Asam Lemak Jenuh dan Asama Lemak Tak Jenuh "Trans" Terhadap Kesehatan. Media Peneliti dan Pengembangan Kesehatan, 19, pp.13-20. 